\title{
Efeito de silicato de cálcio e magnésio no crescimento inicial de milho transgênico
}

\section{João Paulo Freitas de Souza ${ }^{1}$, Gustavo Luís Mamoré Martins ${ }^{1}$, Amanda Casagrande Pereira ${ }^{1}$, Flávio Ferreira da Silva Binotti ${ }^{1}$, Wilson Itamar Maruyama ${ }^{1}$}

${ }^{1}$ Universidade Estadual de Mato Grosso do Sul - UEMS, Unidade Universitária de Cassilândia, MS, Brasil. E-mail: gustavomamore@yahoo.com.br, amanda_tanabi@hotmail.com.br, binotti@uems.br,wilsonmaruyama@uems.br

Recebido: 13/08/2015; Aceito: 07/09/2015.

\section{RESUMO}

O fornecimento do silício pode estimular o desenvolvimento vegetativo e a produção vegetal. Desse modo, o objetivo do trabalho foi avaliar o efeito da aplicação de silicato de cálcio e magnésio no crescimento inicial de plântulas de milho transgênico. O experimento foi conduzido em casa de vegetação na área experimental da Universidade Estadual de Mato Grosso do Sul (UEMS), Unidade Universitária de Cassilândia-MS. O delineamento experimental utilizado foi o inteiramente casualizado (DIC) com cinco tratamentos e cinco repetições. Os tratamentos foram constituídos por cinco doses de silicato de cálcio e magnésio: $0,18,24,30$ e $36 \mathrm{~g} \mathrm{dm}^{-3}$. Após seis meses da aplicação do silicato de cálcio e magnésio foi realizado a semeadura do híbrido Dekalb 310 PRO 2. Foi avaliado o índice de velocidade de emergência, altura de plantas, diâmetro do colmo, área foliar, matéria seca da parte aérea e matéria seca das raízes. As doses de silicato de cálcio e magnésio afetaram significativamente o índice de velocidade de emergência, sendo o maior valor obtido com a aplicação da maior dose de silicato (36 g $\left.\mathrm{dm}^{-3}\right)$. As maiores doses de silicato de cálcio e magnésio proporcionaram maior altura de plantas, diâmetro do colmo, área foliar, matéria seca da parte aérea e raiz.

Palavras-chave: Zea mays, adubação silicatada, desenvolvimento vegetativo.

\section{Effect of calcium and magnesium silicate on initial growth of transgenic maize crop}

\section{ABSTRACT}

The supply of silicon can stimulate plant growth and crop production. Thus, the objective of this study was to evaluate the effect of calcium and magnesium silicate in the initial growth of transgenic maize crop. The experiment was conducted in a greenhouse at the experimental area of the Mato Grosso do Sul State University (UEMS) in Cassilândia-MS, Brazil. The experimental design was completely randomized with five treatments and five repetitions. The treatments consisted of five rates of calcium and magnesium silicate: $0,18,24,30$ and $36 \mathrm{~g}$ $\mathrm{dm}^{-3}$. After six months of calcium silicate and magnesium application was carried out sowing the hybrid Dekalb 310 PRO 2. The emergency rate index, plant height, stem diameter, leaf area, shoot dry matter and root dry matter were measured. Calcium and magnesium silicate rates affected the emergence rate index, being the highest value obtained with the use of higher silicate rate $\left(36 \mathrm{~g} \mathrm{dm}^{-3}\right.$ of silicate). The largest calcium and magnesium silicate rates provided greater plant height, stem diameter, leaf area, dry matter of shoot and root

Key words: Zea mays, silicon fertilization, vegetative development. 


\section{Introdução}

O milho constitui uma excelente fonte de carboidratos e, portanto, possui grande participação na alimentação humana e animal. Essa elevada demanda reflete nos campos de produção, onde a cultura é cultivada em grandes áreas. A estimativa nacional da área total de milho cultivado no verão e safrinha foi de aproximadamente 15.364 milhões de hectares, com produtividade média estimada em $5122 \mathrm{~kg} \mathrm{ha}^{-1}$ (CONAB, 2015).

A expansão da cultura do milho no Brasil tem sido acompanhada de um crescente aumento no custo de produção devido a necessidade de grande volume de defensivos agrícolas, corretivos e fertilizantes aplicados nas lavouras. Desse modo, buscam-se alternativas que promovam a redução do uso de insumos na cultura. Dentre as técnicas adotadas, em 2010 foi aprovada a tecnologia da Monsanto, VT PRO 2, híbridos de milho com a combinação das tecnologias Roundup $\operatorname{Read}^{\circledR}$ e YieldGard ${ }^{\circledR}$ VT PRO, tolerantes ao herbicida glifosato e as três principais lagartas do milho. Essa cultivar transgênica tem apresentado boa produtividade, resistência à seca, doenças e pragas, garantindo a redução no uso de defensivos.

Outra forma de melhorar o uso de insumos agrícolas é a utilização de silicatos que são fontes de silício ( $\mathrm{Si}$ ). O Si após absorvido pelas plantas é depositado nas paredes das células da epiderme fortalecendo a estrutura (DALASTRA et al., 2011) e protegendo contra o ataque de pragas e doenças (RODRIGUES et al., 2011). A utilização de silicato de cálcio e magnésio se torna ainda mais interessante pela sua capacidade corretiva da acidez do solo, devido a formação de hidroxilas que neutralizam íons $\mathrm{H}^{+}$presentes na solução do solo (LIMA FILHO, 2011), além de ser uma fonte de cálcio e magnésio.

Diversos outros benefícios são proporcionados pelo Si nas plantas, como a diminuição da transpiração, maior acúmulo de matéria seca e número de folhas, maior rigidez dos tecidos estruturais proporcionando folhas mais ereta e, assim, maior capacidade fotossintética, diminuição de acamamento e competição por luz (EPSTEIN, 1999). O Si fortifica estruturas da parede celular, conferindo aumento da lignificação, ativação de mecanismos específicos como produção de fitoalexinas e a síntese de proteínas relacionadas à patogênese (FAWE et al., 2001). Pode atuar na constituição de barreira física, resultando na ativação mais rápida e extensiva dos mecanismos de defesa, pré e pós-formados da planta (CHÉRIF et al., 1992).

No Brasil, Reis et al. (2007) relataram que os principais produtos utilizados como fontes de silício são: silicato de cálcio e magnésio em pó (Agrosilício $\left.{ }^{\circledR} / \operatorname{Recmix}^{\circledR}\right) \quad\left(23,0 \%\right.$ de $\left.\mathrm{SiO}_{2}\right)$, silicato de cálcio e magnésio granulado (Agrosilício ${ }^{\circledR} /$ Agronelli ${ }^{\circledR}$ )
(21,4\% de $\left.\mathrm{SiO}_{2}\right)$, Termofosfato Yoorin (20,3\% de $\left.\mathrm{SiO}_{2}\right)$, silicato de potássio $\left(\right.$ Fertisil $\left.^{\circledR}\right)\left(25,6 \%\right.$ de $\left.\mathrm{SiO}_{2}\right)$ e silicato de potássio $\left(\mathrm{Sili}-\mathrm{K}^{\circledR}\right)\left(26,0 \%\right.$ de $\left.\mathrm{SiO}_{2}\right)$.

Diversas são as fontes de $\mathrm{Si}$ existentes com utilização agrícola, porém, as escórias siderúrgicas (silicatos) são de baixo custo, uma vez que é obtido de resíduos da indústria, o que diminui seu custo e viabiliza sua utilização (KORNDORFER et al., 2002). Desse modo, estudos que indiquem a melhor forma de aproveitamento dessa fonte para a agricultura se fazem necessários.

Apesar de vários estudos constatarem a eficiência do uso Si na nutrição de plantas, Freitas et al. (2011) estudando o efeito da aplicação foliar de Si não obteve resultados positivos no crescimento de plantas de milho. A maioria das pesquisas com uso do $\mathrm{Si}$ em milho foram desenvolvidas com cultivares convencionais, considerando o efeito em pragas da cultura (GOUSSAIN et al., 2002). Pouca ênfase tem sido dada ao efeito do Si no crescimento de plântulas de milho transgênicas.

Com base no exposto, o objetivo deste estudo foi avaliar o efeito da aplicação de silicato de cálcio e magnésio no crescimento inicial de milho transgênico (Zea mays L., híbrido DKB 310 PRO 2).

\section{Material e Métodos}

O experimento foi conduzido em casa de vegetação na Universidade Estadual de Mato Grosso do Sul, Unidade Universitária de Cassilândia (1907'21', S, $51^{\circ} 43$ ' 15 " W e altitude de $\left.516 \mathrm{~m}\right)$, no período de janeiro a julho de 2014. O clima da região segundo a classificação climática de Koppen é do tipo Aw (clima tropical chuvoso). O solo utilizado foi um Neossolo Quartzarênico de textura média, e as principais propriedades químicas são apresentadas na Tabela 1 .

$\mathrm{O}$ delineamento experimental utilizado foi $\mathrm{o}$ inteiramente casualizado (DIC) com cinco tratamentos e cinco repetições, totalizando 25 unidades experimentais. Os tratamentos foram constituídos por cinco doses de silicato de cálcio e magnésio $\left(0,18,24,30\right.$ e $\left.36 \mathrm{~g} \mathrm{dm}^{-3}\right)$. A fonte de silicato utilizada foi o Agrosilício (35\% de $\mathrm{CaO}, 10 \%$ de $\mathrm{MgO}$ e $22 \%$ de $\mathrm{SiO}_{2}$ ). As doses de silicato foram aplicadas ao solo e permaneceram incubadas por um período de 6 meses. Após o período de incubação do silicato, o solo foi acondicionado em bandejas plásticas contendo $6 \mathrm{dm}^{3}$ de solo.

A semeadura híbrido de milho Dekalb 310 PRO 2 foi realizada no dia 01/07/2014. Cada bandeja alocou 50 sementes distribuídas uniformemente. Por ocasião da semeadura do milho foram aplicados $0,66 \mathrm{~g}$ de ureia, 3,32 g de super simples e $0,84 \mathrm{~g}$ de cloreto de potássio em cada vaso. Avaliou-se o teste de emergência, evidenciando porcentagem de germinação de $91 \%$. 
Tabela 1. Resultado da análise química do solo utilizado no experimento. Cassilândia, MS. 2014.

\begin{tabular}{|c|c|c|c|c|c|c|c|c|c|}
\hline \multirow{2}{*}{$\begin{array}{l}P_{\text {Resina }} \\
\mathrm{mg} \mathrm{dm}^{-3}\end{array}$} & \multirow{2}{*}{$\begin{array}{l}\text { M.O. } \\
\text { g dm}^{-3}\end{array}$} & \multirow{2}{*}{$\begin{array}{l}\mathrm{pH} \\
\left(\mathrm{CaCl}_{2}\right)\end{array}$} & $\mathrm{K}$ & $\mathrm{Ca}$ & $\mathrm{Mg}$ & $\mathrm{H}+\mathrm{Al}$ & \multirow{2}{*}{$\begin{array}{l}\mathrm{m} \\
\%\end{array}$} & \multirow[t]{2}{*}{$\mathrm{V}$} & \multirow[t]{2}{*}{ CTC } \\
\hline & & & $\mathrm{mmc}$ & & & & & & \\
\hline 3,1 & 13,7 & 4,1 & 0,08 & 0,30 & 0,20 & 4,1 & 67,2 & 12,4 & 4,7 \\
\hline
\end{tabular}

M.O.: matéria orgânica.

Para uniformizar a irrigação foi feito o cálculo da capacidade de campo com resultado de $1800 \mathrm{~mL}$ de água por bandeja e, então, se tomou como uso $15 \%$ deste valor $(270 \mathrm{~mL})$ por bandeja diariamente.

Ao quarto dia após a semeadura iniciou-se a contagem do número de plântulas para cálculo do índice de velocidade de emergência (IVE) que se estendeu até o $13^{\circ}$ dia (momento em que as plantas começaram a entrar em competição) e, então, no $14^{\circ}$ dia foram realizadas as avaliações de altura de plantas (média de todas as plantas), diâmetro de colmo (20 plantas por unidade), área foliar (20 plantas por unidade) e matéria seca da parte aérea e das raízes de milho.

Os dados obtidos foram submetidos à análise de variância pelo teste $\mathrm{F}(\mathrm{P}=0,05)$ e análise de regressão polinomial para as doses de silicato de cálcio e magnésio, utilizando o programa estatístico SISVAR (FERREIRA, 2011). Na análise de regressão, os coeficientes dos componentes de cada modelo foram testados, escolhendo-se os modelos significativos com maior coeficiente de determinação $\left(\mathrm{R}^{2}\right)$.

\section{Resultados e Discussão}

O índice de velocidade de emergência (IVE) do milho foi afetado significativamente pelas doses de silicato de cálcio e magnésio (Figura 1). O IVE de plantas de milho transgênico se ajustou a regressão linear positiva $(\mathrm{p}<0,05)$, com maior valor obtido com o uso da maior dose de silicato $\left(36 \mathrm{~g} \mathrm{dm}^{-3}\right)$ (Figura 1).

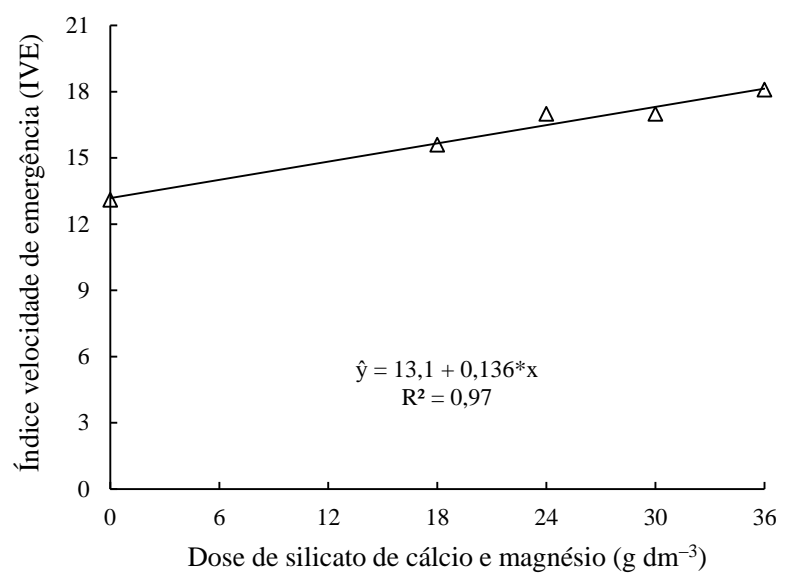

Figura 1. Índice de velocidade de emergência (IVE) do milho transgênico em função de doses de silicato de cálcio e magnésio. Cassilândia, MS. 2014.
A altura de plântulas de milho transgênico (Figura 2) também foi influenciada pelas doses de silício $(p<0,05)$. Para o diâmetro de colmos das plântulas de milho (Figura 3) houve efeito positivo em função das doses de silicato de cálcio e magnésio $(\mathrm{p}<0,05)$. $\mathrm{O}$ diâmetro de colmo aumentou com o incremento da dose de silicato de cálcio e magnésio. Resultados diferentes foram observados por Cessa et al. (2011), que estudando a absorção de fósforo e crescimento do sorgo em função da aplicação de Si e $\mathrm{P}$, não constataram diferença no diâmetro de colmo em função das doses de Si.

Houve incremento linear da área foliar do milho ( $p<0,05)$ em função do aumento da dose de silicato (Figura 4). A maior área foliar foi importante para o crescimento inicial das plântulas de milho. Esses resultados são semelhantes aos reportados por Lima et al. (2011), que constataram efeito positivo da aplicação de silicato de sódio em solução nutritiva na área foliar de plantas de milho. A área foliar é importante para caracterizar o crescimento das plantas porque determina a quantidade de radiação solar interceptada para a fotossíntese. O maior crescimento pode incrementar o aproveitamento da radiação solar disponível no início do ciclo do milho (ALMEIDA et al., 2003).

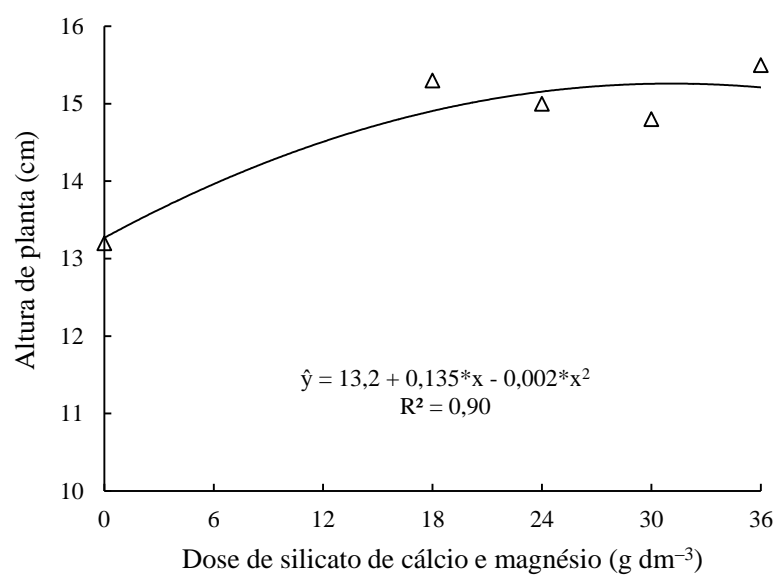

Figura 2. Altura da parte aérea das plantas $(\mathrm{cm})$ de milho transgênico em função de doses de silicato de cálcio e magnésio. Cassilândia, MS. 2014. 


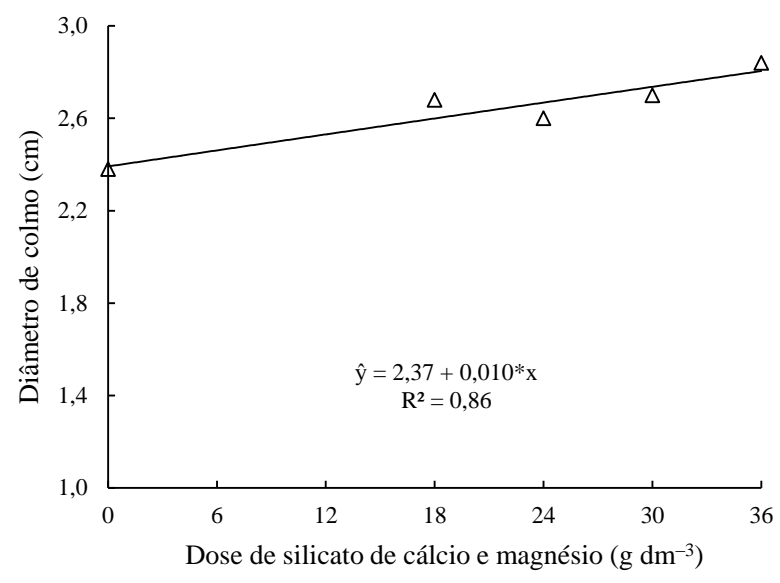

Figura 3. Diâmetro de colmo $(\mathrm{cm})$ de milho transgênico em função de doses de silicato de cálcio e magnésio. Cassilândia, MS. 2014

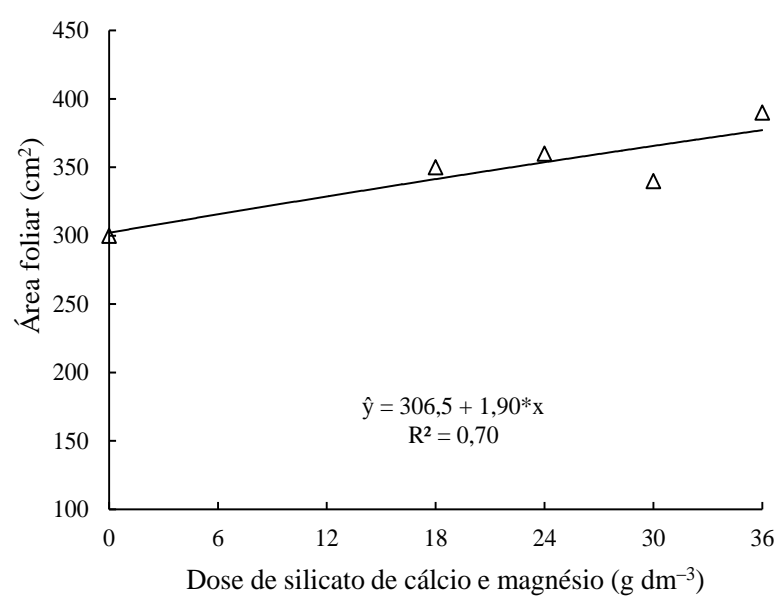

Figura 4. Área foliar $\left(\mathrm{cm}^{2}\right)$ de milho transgênico em função de doses de silicato de cálcio e magnésio. Cassilândia, MS. 2014.

A produção de matéria seca da parte aérea de milho foi afetada pela aplicação das doses de silicato de cálcio e magnésio (Figura 5). Houve aumento da matéria seca da parte aérea em função do aumento da dose de silicato $(\mathrm{p}<0,05)$, sendo que a maior dose utilizada $\left(36 \mathrm{~g} \mathrm{dm}^{-3} \mathrm{de}\right.$ solo) resultou na máxima produção de matéria seca da parte aérea.

A produção de matéria seca das raízes de milho (Figura 6) aumentou com as doses de silicato de cálcio e magnésio $(\mathrm{p}<0,05)$.

Os efeitos benéficos da aplicação de silicato de cálcio e magnésio no crescimento das plântulas de milho podem ser devido ao efeito corretivo da acidez e neutralização do Al tóxico (PRADO; FERNANDES, 2000) pelo $\mathrm{Ca}$ e $\mathrm{Mg}$ no solo e aumento no $\mathrm{pH}$ e saturação de bases que antes da aplicação dos tratamentos apresentaram valores baixos (Tabela 1). Sintomas visuais de deficiência nutricional foram constatados em todas as repetições do tratamento sem a aplicação de silicato (controle), onde as folhas apresentaram estrias paralelas as nervuras e raízes acima da superfície do solo.

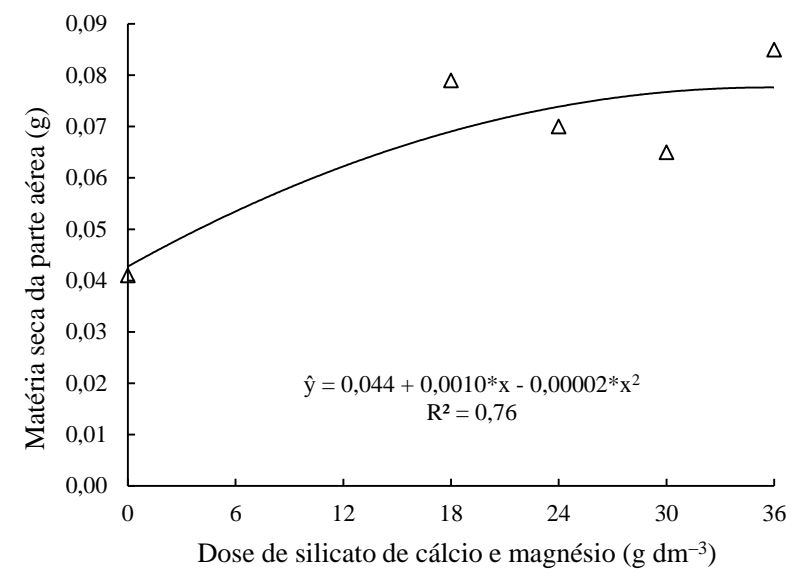

Figura 5. Matéria seca da parte aérea (g) das plântulas de milho transgênico em função de doses de silicato de cálcio e magnésio. Cassilândia, MS. 2014.

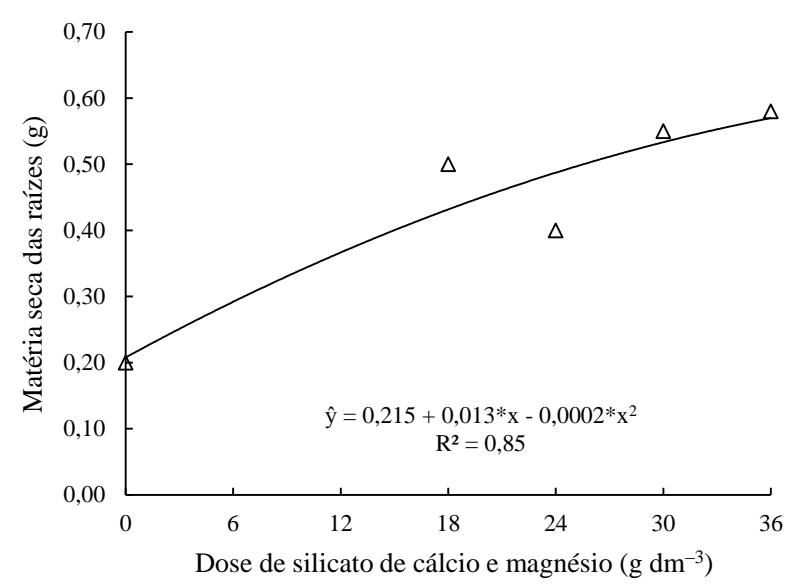

Figura 6. Matéria seca das raízes (g) de milho transgênico em função de doses de silicato de cálcio e magnésio. Cassilândia, MS. 2014.

\section{Conclusão}

A aplicação de silicato de cálcio e magnésio melhorou a velocidade de emergência e o crescimento inicial das plântulas de milho.

\section{Referências Bibliográficas}

ALMEIDA, M. L.; SANGOI, L.; NAVA, I.C.; GALIO, J.; TRENTIN, P.S.; RAMPAZZO, C. Crescimento inicial de milho e sua relação com o rendimento de grãos. Ciência Rural, Santa Maria-RS, v. 33, n. 2, p. 189-194, 2003.

CESSA, R, M. A.; NOVELINO, J. O.; VITORINO, A. C. T.; MAUAD, M. Absorção de fósforo e crescimento do Sorgo em função da aplicação de silício e fósforo em Latossolo Vermelho distroférrico. Agrarian, Dourados-MS, v. 34, n. 1, 2011.

CHÉRIF, M., BENHAMOU, N., MENZIES, J.G.; BÉLANGER, R.R. Silicon induced resistance in cucumber plants against Pythium ultimum. Physiological and Molecular Plant Pathology. East Lansing, v. 41, n. 6, p. 411-425, 1992.

CONAB. COMPANHIA NACIONAL DE ABASTECIMENTO. Acompanhamento da safra brasileira - Grãos. Milho. Disponível em: < http://www.conab.gov.br/>. Acesso em: 30 jul. 2015. 
DALASTRA, C.; CAMPOS, A. R.; FERNANDES, F. M.; MARTINS, G. L. M.; CAMPOS, Z. R. Silício como indutor de resistência no controle do tripes do prateamento Enneothrips flavens Moulton, 1941 (Thysanoptera: Thripidae) e seus reflexos na produtividade do amendoinzeiro. Ciência e Agrotecnologia, Lavras-MG, v.35, n.3, p.531-538, 2011.

EPSTEIN, E. Silicon. Annual Review of Plant Physiology and Plant Molecular Biology, Palo Alto, v.50, p.641-664, 1999.

FERREIRA, D. F. Sisvar: a computer statistical analysis system. Ciência e Agrotecnologia, Lavras-MG, v. 35, n. 6, p. 1039-1042, 2011.

FREITAS, L. B. COELHO, E. M.; MAIA, S. C. M.; SILVA, T. R. B. Adubação foliar com silício na cultura do milho. Revista Ceres, Viçosa-MG, v. 58, n. 2, 2011.

GOUSSAIN, M.M.; MORAES, J.C.; CARVALHO, J.G.; NOGUEIRA, N.L.; ROSSI, M.L. Efeito da aplicação de silício em plantas de milho no desenvolvimento biológico da lagarta-do-cartucho Spodoptera frugiperda (J.E.Smith) (Lepidoptera: Noctuidae). Neotropical Entomology, Londrina-PR, v. 31, n. 2, p. 305-310, 2002.
KORNDORFER, G. H.; PEREIRA, H. S.; CAMARGO, M. S. Silicato de cálcio e magnésio na agricultura. UberlândiaMG: UFU, 2002, 15 p.

LIMA, M. A.; CASTRO, V. F.; VIDAL, J. B.; ENEASFILHO, J. Aplicação de silício em milho e feijão-de-corda sob estresse salino. Revista Ciência Agronômica, Fortaleza-CE, v. 42, n. 2, p. 398-403, 2011.

PRADO, R. M.; FERNANDES, F. M. Escória de siderurgia e calcário na correção da acidez do solo cultivado com cana-deaçúcar em vaso. Scientia Agricola, Piracicaba-SP, v.57, n.4, p.739-744, 2000.

REIS, T. H. P.; GUIMARÃES, P. T. G.; FIGUEIRE, F. C.; POZZA, A. A. A.; NOGUEIRA, F. D.; RODRIGUES, C. R. $O$ silício na nutrição e defesa de plantas. Belo HorizonteMG: EPAMIG, 2007. 119 p.

RODRIGUES, F. A.; OLIVEIRA, L. A.; KORNDÖRFER, A. P.; KORNDÖRFER, G. H. Silício: Um elemento benéfico e importante para as plantas. Informações Agronômicas, Piracicaba-SP, n. 134, p. 14-28, 2011. Disponível em < http://www.ipni.net/publication/ia-brasil.nsf/ >. Acesso em: 16 nov. 2014. 